\title{
Localization of SNARE proteins and secretory organelle proteins in astrocytes in vitro and in situ
}

\author{
Alexander Wilhelm ${ }^{\mathrm{a}}$, Walter Volknandt ${ }^{\mathrm{a}, *}$, David Langer ${ }^{\mathrm{a}}$, Christine Nolte ${ }^{\mathrm{b}}$, \\ Helmut Kettenmann ${ }^{\mathrm{b}}$, Herbert Zimmermann ${ }^{\mathrm{a}}$ \\ ${ }^{a}$ Biozentrum der J.W. Goethe-Universität, AK Neurochemie, Zoologisches Institut, Marie-Curie-Str. 9, D-60439 Frankfurt am Main, Germany \\ b Max-Delbrueck-Center for Molecular Medicine, Robert-Roessle-Str. 10, Berlin-Buch, D-13092 Berlin, Germany
}

Received 12 August 2003; accepted 13 November 2003

\begin{abstract}
Astrocytes are capable of regulated release of messenger molecules. Astrocytes cultured from new born rodent brain express a variety of classical presynaptic proteins. We investigated the question whether the capability to express synaptic proteins in culture was a feature only of immature astrocytes, and whether these proteins were also expressed by astrocytes in situ. Experiments were performed with transgenic mice expressing the enhanced green fluorescent protein under the control of the human glial fibrillary acidic protein promoter. Using double fluorescence and astrocytes cultured from 1 to 16 day-old animals we show that the astrocytic expression of synaptic proteins in culture is invariant of the age of donor animals. Culturing can induce the astrocytic expression of specific synaptic proteins such as SV2, synaptophysin and SNAP-25. Astrocytes in brain sections of 1-16 day-old animals revealed a punctuate immunofluorescence for secretory carrier membrane protein (SCAMP), SNAP-23, synaptobrevin II, and cellubrevin, to a minor extent for SNAP-25 and synaptophysin, and none for SV2. Our results demonstrate that cultured astrocytes express synaptic proteins not present in situ. Nevertheless, astrocytic organelles in situ are equipped with molecules that could be involved in regulated exocytosis of messenger substances.
\end{abstract}

(C) 2003 Elsevier Ireland Ltd and The Japan Neuroscience Society. All rights reserved.

Keywords: Glia; Mouse; Synaptic vesicle; Vesicle protein; SNARE

\section{Introduction}

Astrocytes take an active part in information processing within the nervous system, acting as receptive as well as signaling elements. They directly respond to synaptically released messengers and communicate, via signaling substances, with neurons in a reciprocal manner (Araque et al., 2001; Haydon et al., 2001; Pasti et al., 1997; Vesce et al., 1999). Even more, spontaneous astrocytic $\mathrm{Ca}^{2+}$-oscillations in situ can drive NMDA-receptor-mediated neuronal excitation (Parri et al., 2001). These observations point to unexpected functional similarities between astrocytes and nerve cells.

Earlier evidence had suggested that low molecular weight messengers such as glutamate, aspartate or taurine are released from cultured astrocytes exclusively by

\footnotetext{
* Corresponding author. Tel.: +49-69-79829603; fax: +49-69-79829606.

E-mail address: volknandt@zoology.uni-frankfurt.de (W. Volknandt).
}

plasma membrane-located transporters. More recently, receptor-mediated astrocytic release of a number of signaling substances has been demonstrated, implicating the existence of a regulated release pathway (Araque et al., 2001). Astrocytic release of glutamate (Bezzi et al., 1998; Parpura et al., 1994; Pasti et al., 2001), ATP (Bal-Price et al., 2002; Coco et al., 2003), of the secretory granule protein secretogranin II (Calegari et al., 1999), and of atrial natriuretic peptide (Krzan et al., 2003) were found to depend on an increase in intracellular $\mathrm{Ca}^{2+}$ concentrations. Furthermore, prolonged incubation of astrocytes with the botulinum neurotoxins $\mathrm{A}, \mathrm{C}_{1}$ and $\mathrm{B}$, or with tetanus toxin (which cleave the SNARE proteins SNAP-25, syntaxin I, and synaptobrevin II/cellubrevin, respectively) resulted in attenuated receptor-evoked glutamate release (Araque et al., 2000; Jeftinija et al., 1997; Pasti et al., 2001). These observations imply that astrocytes contain vesicular storage compartments and employ molecular mechanisms of release resembling exocytosis in nerve cells. 
Several studies have identified proteins in cultured astrocytes that are typically associated with synaptic vesicles or involved in exocytosis. These include the synaptic vesicle proteins synaptobrevin II/VAMP II (a v-SNARE), synaptotagmin I, synaptophysin, rab3, rab5, or synapsin I, the two t-SNAREs SNAP-25, and syntaxin I, or also the more ubiquitous SNARE proteins cellubrevin and SNAP-23 (Hepp et al., 1999; Madison et al., 1996; Maienschein et al., 1999; Megías et al., 2000; Parpura et al., 1995; Volknandt, 2002). Cultured astrocytes also contain electron-dense granules (Calegari et al., 1999; Maienschein et al., 1999) that have been shown to store secretogranin (Calegari et al., 1999).

We have previously shown that astrocytes cultured from new born rats express a plethora of synaptic proteins and in addition that the expression of individual proteins changes with culture time (Maienschein et al., 1999; Volknandt, 2002). The possibility remained, however, that the astrocytic expression of synaptic proteins was an exclusive feature of immature astrocytes isolated from neonatal animals. Furthermore, the expression of synaptic proteins could have been induced by transferring astrocytes into tissue culture. In order to readily identify astrocytes in vitro and in situ, we performed experiments with transgenic mice in which astrocytes express the enhanced green fluorescent protein (EGFP) under the control of the human glial fibrillary acidic protein (GFAP) promoter (Matthias et al., 2003; Nolte et al., 2001). Using this animal model, we investigated the question whether the protein expression pattern of cultured astrocytes varies with the age of donor animals. In addition, we analyzed the association of organellar proteins in EGFP-positive astrocytes immediately after isolation and during subsequent culture as well as in brain sections in situ.

\section{Materials and methods}

\subsection{Animals}

Experiments were performed with transgenic mice (new born to 16 day-old) in which astrocytes are labeled by the enhanced green fluorescent protein under the control of the human glial fibrillary acidic protein promoter (Nolte et al., 2001). Adequate measures were taken to minimize pain or discomfort of experimental animals.

\subsection{Preparation of acutely isolated astrocytes and astrocyte cultures}

Primary astroglial cultures were prepared and cultured as previously described (Maienschein et al., 1999). In brief, brains of new born (postnatal day 1) mice were transferred into chilled Hank's buffered saline solution $\left(4{ }^{\circ} \mathrm{C}\right)\left(+\mathrm{Ca}^{2+} / \mathrm{Mg}^{2+}\right.$; Gibco BRL, Germany). Meninges and larger blood vessels were removed using a stereo microscope. The tissue was cut into small pieces and sub- sequently dissociated by trituration using a $1 \mathrm{ml}$ pipette and incubation in a collagenase A cocktail (Roche Diagnostics, Mannheim, Germany; clostridiopeptidase A activity: $0.02 \mathrm{U} / \mathrm{ml}$, clostripain: $0.39 \mathrm{U} / \mathrm{ml}$, proteases (Azocoll): $2.66 \mathrm{U} / \mathrm{ml}$, trypsin (BAEE): $0.03 \mathrm{U} / \mathrm{ml}$; Lot. No. 85761526 ) for $30 \mathrm{~min}$ at $37^{\circ} \mathrm{C}$ with additional shaking every $5 \mathrm{~min}$. The cell suspension was passed through nylon gauze $(50 \mu \mathrm{m})$ and the filtrate was centrifuged for $5 \mathrm{~min}$ at $200 \times g_{\text {av }}$. The supernatant was discarded and the cell pellet was resuspended in $10 \mathrm{ml}$ of medium. This step was repeated twice. For direct analysis of acutely isolated cells the pellet was resuspended in Hank's buffered saline solution and the cells were centrifuged onto poly-D-lysine (>300,000 kDa; Sigma, Deisenhofen, Germany) coated glass cover slips. For the analysis of cultured astrocytes, the cells were plated on poly-D-lysine-coated glass cover slips in 24-well tissue culture plates (Dunn, Asbach, Germany) and kept for up to 16 DIV in DMEM supplemented with $9 \%$ fetal calf serum, $4 \mathrm{mM}$ L-alanyl-L-glutamine, $90 \mathrm{U} / \mathrm{ml}$ penicillin, and $90 \mu \mathrm{g} / \mathrm{ml}$ streptomycin at $37^{\circ} \mathrm{C}$, $5 \% \mathrm{CO}_{2}$ and a relative humidity of $95 \%$. Medium and reagents were obtained from Gibco BRL (Eggenstein, Germany).

\subsection{Immunocytochemistry of acutely isolated or cultured cells}

Cells were analyzed directly after isolation or after varying culture times. After a $5 \mathrm{~min}$ wash in physiological saline solution (in $\mathrm{mM}$ : $130 \mathrm{NaCl}, 4.8 \mathrm{KCl}, 1.2 \mathrm{KH}_{2} \mathrm{PO}_{4}$, $25.5 \mathrm{NaHCO}_{3}, 11.0$ glucose, $1.2 \mathrm{MgSO}_{4}, 2 \mathrm{CaCl}_{2}$, adjusted to $\mathrm{pH} 7.4$ ) at $37^{\circ} \mathrm{C}$ to remove excess medium cells were fixed in $4 \%$ paraformaldehyde in phosphate buffered saline (PBS, $137 \mathrm{mM} \mathrm{NaCl}, 3 \mathrm{mM} \mathrm{KCl}, 10 \mathrm{mM} \mathrm{Na}_{2} \mathrm{HPO}_{4}$, $1.8 \mathrm{mM} \mathrm{KH}_{2} \mathrm{PO}_{4}$, $\mathrm{pH} 7.4$, for $10 \mathrm{~min}$ at room temperature). After washing with PBS cells were permeabilized with PBS containing Triton X-100 (0.1\%, $15 \mathrm{~min})$. Non-specific binding sites were blocked with $5 \%$ of bovine serum albumin (BSA) in PBS, followed by application of the primary antibody, which was diluted in PBS containing $1 \%$ BSA and $0.1 \%$ Triton X-100. After several washing steps, the respective secondary antibodies were applied. In negative controls, the primary antibodies were omitted. After washing with PBS, the cells were coverslipped in 1,4 diazabicyclo-[2,2,2]-octane glycerol mounting media (Heimer and Taylor, 1974). Cells were examined using a Zeiss Axiophot microscope equipped with a MCID imaging analysis system (Imaging Research, St. Catherines, Ontario, Canada) or a laser assisted Leica TCS4D (Leica, Bensheim, Germany) true confocal scanner.

\subsection{Immunocytochemistry of tissue sections}

Mice were deeply anaesthetized with pentobarbital $(800 \mathrm{mg} / \mathrm{kg})$ and perfused intracardially with PBS containing heparin $(0.5 \mathrm{mg} / \mathrm{ml})$ followed by perfusion with $100 \mathrm{ml}$ 
of $2 \%$ paraformaldehyde in PBS. Excised brains were immersed in the paraformaldehyde fixative for $2 \mathrm{~h}$ at $4{ }^{\circ} \mathrm{C}$, cryoprotected by immersion in PBS containing 30\% sucrose, frozen in isopentane $\left(-80^{\circ} \mathrm{C}\right)$, and stored at $-80^{\circ} \mathrm{C}$ until cryo-sectioning. Frozen coronal sections of 10-14 $\mu \mathrm{m}$ were prepared from the hippocampal region of the forebrain, subsequently deposited on poly-D-lysine-coated slides and allowed to dry for $1 \mathrm{~h}$. The dry sections were stored at $4{ }^{\circ} \mathrm{C}$ until further processing. For indirect immunocytochemistry sections were incubated with PBS containing $0.5 \%$ Triton $\mathrm{X}-100$ for $30 \mathrm{~min}$. Non-specific binding was blocked with $5 \%$ BSA in PBS. Antibodies were diluted with PBS containing $1 \%$ BSA and $0.1 \%$ Triton X-100. Sections were incubated with antibodies for $3 \mathrm{~h}$ at room temperature. After three washes with PBS, they were incubated with secondary antibodies for $1 \mathrm{~h}$ at room temperature. After washing with PBS, the sections were coverslipped in 1,4 diazabicyclo-[2,2,2]-octane glycerol mounting media. Sections were examined with a laser assisted Leica TCS4D (Leica, Bensheim, Germany) true confocal scanner using two different objectives $(63 x / 1.40$ oil, 8/0.17/C PL APO with extremely good chromatic correction also in the $z$-axis and 100x/1.30 oil, 8/0.17/D PL FluoTAR). Both objectives yielded identical results. Green and red fluorescence was monitored separately and evaluated and further processed using Adobe Photoshop software.

\subsection{Antibodies}

Antibodies against the following proteins were applied: synaptobrevin II/VAMP II, clone 69.1; synaptophysin, clone 7.2; SNAP-23, polyclonal antibody against synthetic peptide DRIDIANARAKKLIDS; secretory carrier membrane protein I (SCAMP I), polyclonal antibody against synthetic peptide SDFDSNPFADPDLN; vesicular proton pump (v-ATPase), polyclonal antibody against synthetic peptide FSFEHIREGKFDE (all Synaptic Systems, Göttingen, Germany); SNAP-25, clone SMI 81 (Biotrend, Köln); SV2, clone CKK 10H4, a gift of Dr. R. B. Kelly (San Francisco); cellubrevin, affinity purified polyclonal antibody (McMahon et al., 1993), a gift of Dr. McMahon (Cambridge, UK); GFAP, clone G-A5, IgG1 isotype (Sigma, Deisenhofen, Germany). Cy3-conjugated secondary antibodies against mouse and rabbit IgGs were obtained from Dianova (Hamburg, Germany). Using Western blotting, the specificity of the antibodies in recognizing the respective antigen in rodent astrocytes has previously been demonstrated (Maienschein et al., 1999; Volknandt, 2002).

\section{Results}

\subsection{Age of donor animals and dependence of organellar protein expression in cultured astrocytes}

To investigate whether the potential to express synaptic proteins was developmentally regulated, astrocytes were isolated from postnatal mice of varying age. In addition, astrocytes were cultured for varying periods of time to monitor possible alterations in protein expression both, as a result of culture time and of animal age. In a first series of experiments, astrocytes were isolated from brains of new born animals and of 2, 3, 7, 11, and 16 day-old mice. Astrocytes were cultured for 2 days (2 DIV) and identified by their EGFP fluorescence. The EGFP fluorescence was evenly distributed within the cell body and throughout the processes. EGFP-positive cells of all animal ages investigated were found to be immunopositive for SNAP-25, SNAP-23, cellubrevin, synaptophysin, and SV2. Fig. 1 presents images from 2 DIV astrocytes derived from 3 and 16 day-old animals. A coarse punctuate immunofluorescence for the synaptic t-SNARE SNAP-25 was observed within the cell body and in the cellular processes of EGFP-positive cells (Fig. 1(A-D)). Similarly the ubiquitous t-SNARE SNAP-23 was found to be expressed at all developmental stages but granular structures were more difficult to discern (Fig. 1(E-H)). The synaptic vesicle proteins synaptophysin and SV2 were both found in association with large punctuate organelles that were distributed throughout the entire cell and within cellular processes (Fig. 1(J-Q)). These data showed that astrocytes cultured from up to 16 day-old mice express synaptic proteins when cultured in vitro.

\subsection{Culturing can induce the expression of astrocytic organellar proteins}

In order to investigate the in situ astrocytic protein expression pattern in more detail, astrocytes were cultured from 11 day-old animals and analyzed immediately after isolation and during a subsequent culture period of up to $8 \mathrm{DIV}$. Acutely isolated cells were found to be immunopositive for SNAP-23 and synaptobrevin II. SNAP-25 and synaptophysin (not shown) could be detected only in a very small proportion of cells $(<5 \%)$ and SV2 was entirely absent. The situation was dramatically altered when cells were cultured. All proteins investigated were abundant after $12 \mathrm{~h}$ in culture. Figs. 2 and 3 show representative results obtained immediately after isolation, and after $12 \mathrm{~h}, 1$ and 8 days of cell culture. In acutely isolated astrocytes, the immunofluorescence for SNAP-25 (Fig. 2(A) and (B)), its homologue SNAP-23 (Fig. 2(J) and (K)) and for synaptobrevin II (Fig. 3(A) and (B)) revealed a fine punctuate distribution. Cells were immunonegative for SV2 (Fig. 3(J) and (K)). With increasing culture time, the immunofluorescence of the various proteins became abundant and associated with larger organelles. This could already be observed after $12 \mathrm{~h}$ in vitro. SNAP-25 (Fig. 2(C) and (D)), SNAP-23 (Fig. 2(L) and (M)) and synaptobrevin II (Fig. 3(C) and (D)) were found to be distributed throughout the cell soma and the cellular processes that had been formed. At 1 and 8 DIV large immunofluorescent spots for SNAP-25 (Fig. 2(E-H)), SNAP-23 (Fig. 2(N-Q)) and synaptobrevin II (Fig. 3(E-H)) were distributed within 


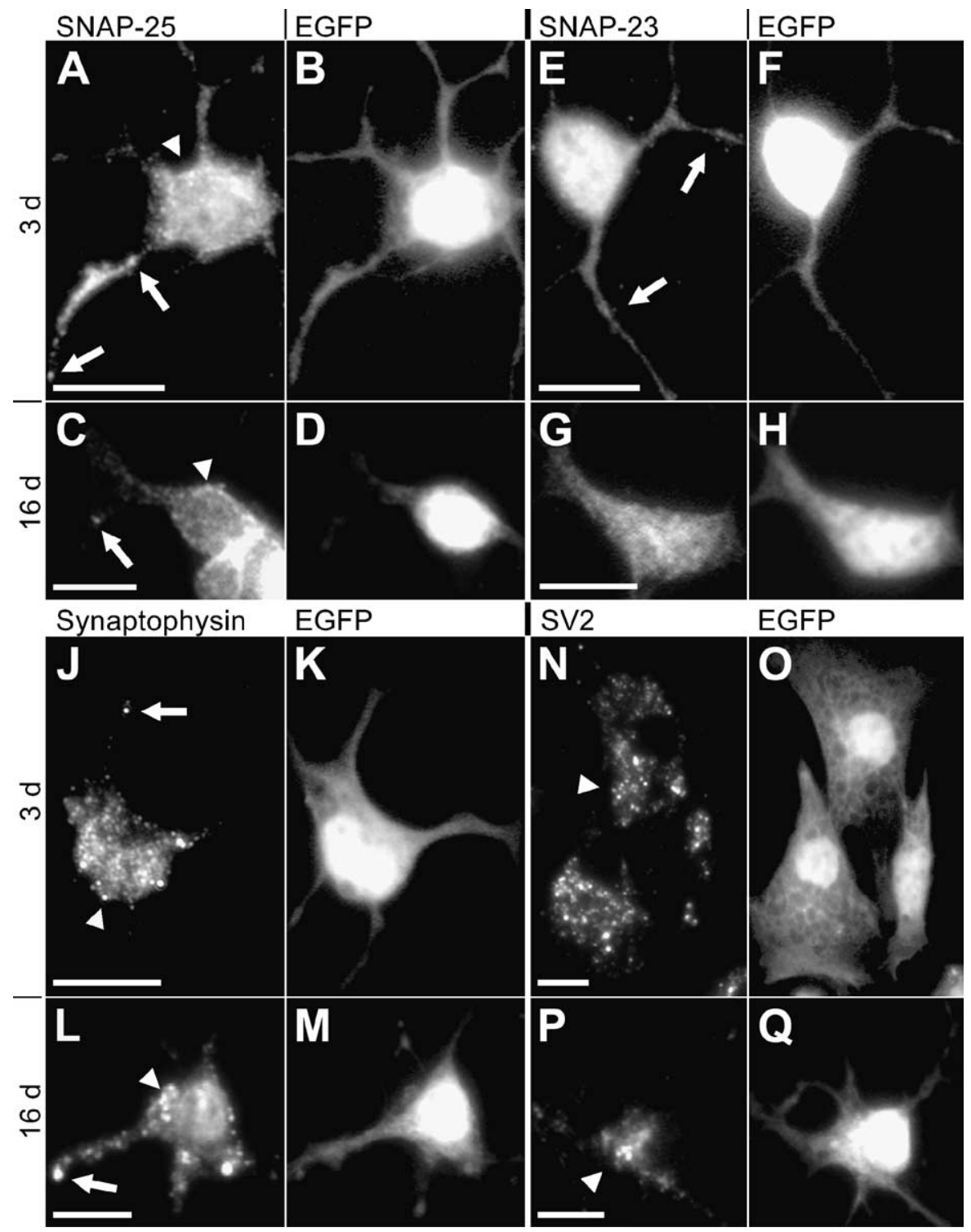

Fig. 1. Immunodetection of synaptic proteins in EGFP-expressing cells. Cells were isolated from 3 days (A, B, E, F; J, K, N, O) and 16 days (C, D, G, H; L, M, P, Q) old animals and analyzed after 2 DIV. A, C, SNAP-25; E, G, SNAP-23; J, L, synaptophysin; N, P, SV2. B, F, D, H, K, O, M, $\mathrm{Q}$ represent the corresponding distribution of EGFP fluorescence. Arrows, punctuate immunofluorescence in cellular extensions; arrow heads, punctuate staining in cell bodies. Images were adjusted to improve brightness and contrast. Scale bars: $10 \mu \mathrm{m}$.

the cell bodies and scattered throughout the cellular processes. The density of the fluorescent spots was highest within the cell soma, with occasional clusters formed within the cellular processes. In accordance with previous results (Maienschein et al., 1999; Volknandt, 2002) immunofluorescence for SNAP-25 decreased with increasing culture time and could be detected only in a few astrocytes at 8 DIV. Already after $12 \mathrm{~h}$, SV2 was found in association with large organellar structures throughout the astrocytes (Fig. 3(L) and (M)). This expression pattern was maintained at 1 and 8 DIV (Fig. 3(N)-(Q)). It corresponded to the high organellar expression of synaptophysin observed in cultured astrocytes (Fig. 1(J) and (D) and Maienschein et al., 1999).

\subsection{Distribution of organellar proteins in astrocytes in tissue sections}

In addition, we analyzed the in situ distribution of a variety of synaptic proteins in coronal sections of the forebrain. For comparison with the in vitro data, animals were investigated after birth (1 day), and after 11 and 16 days. No alteration in the cellular distribution of individual proteins was observed during the time period investigated. Sections were analyzed by confocal microscopy using single confocal optical sections. Following animal perfusion with paraformaldehyde, the soluble EGFP was retained within the astrocytes including their fine cellular ramifications. Cryosections could then be employed for immunofluorescence analysis of organellar 


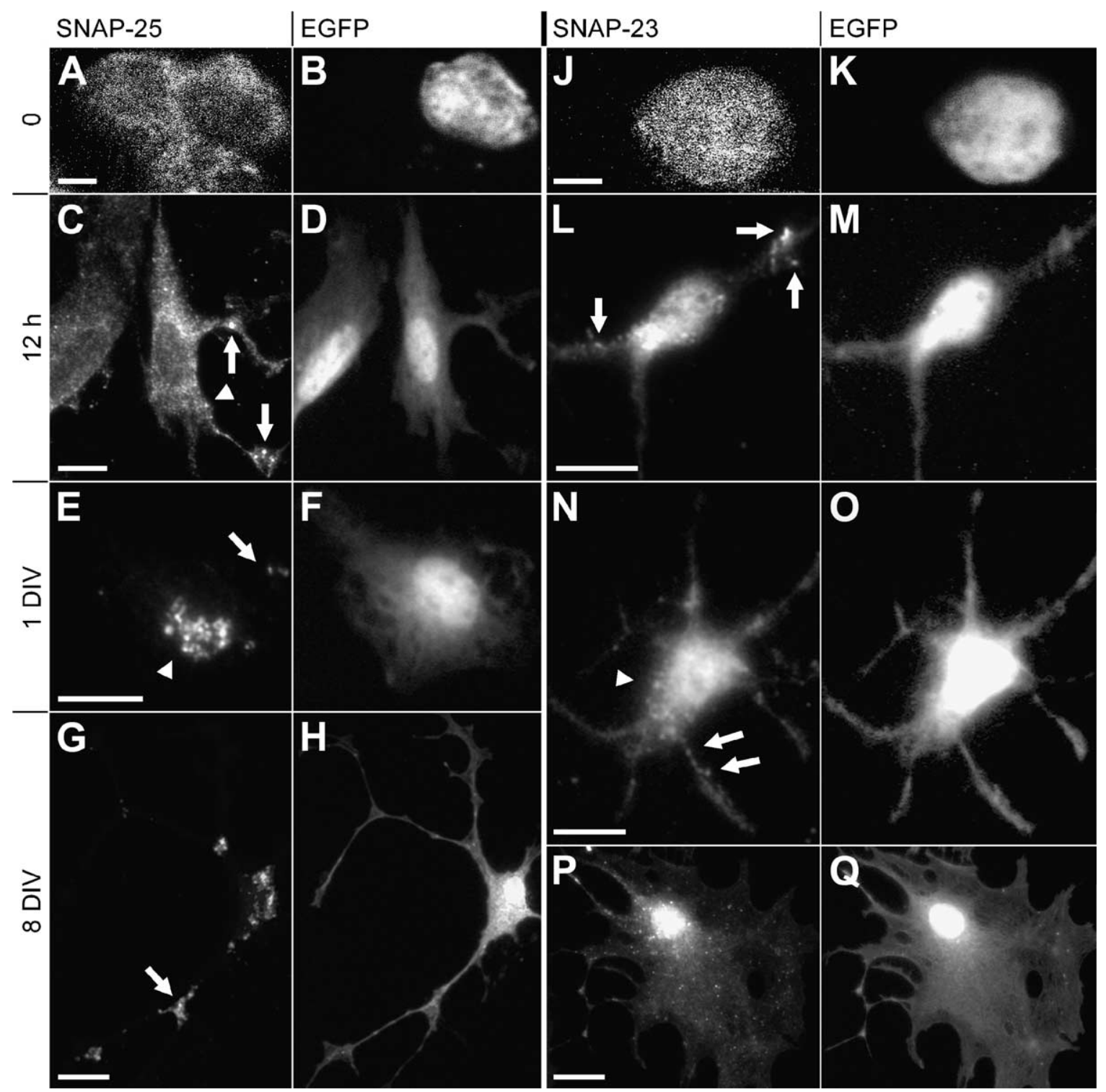

Fig. 2. Immunodetection of SNAP-25 and SNAP-23 in EGFP-expressing cells isolated from 11 day-old animals. Cells were fixed directly after isolation (A, B, J, K) or after culturing for $12 \mathrm{~h}(\mathrm{C}, \mathrm{D}, \mathrm{L}, \mathrm{M}), 1$ DIV (E, F, N, O) and 8 DIV (G, H, P, Q). A, C, E, G, distribution of SNAP-25; J, L, N, P, SNAP-23. B, D, F, H, K, M, O, Q represent the corresponding distribution of EGFP fluorescence. Arrows, punctuate immunofluorescence in cellular extensions; arrow heads, punctuate staining in cell bodies. Images were adjusted to improve brightness and contrast. Scale bars: $10 \mu \mathrm{m}$.

proteins. The analysis of synaptic proteins in brain tissue is hampered by their universal neuronal expression that predominates the fluorescence images obtained (compared to Fig. 4). In order to evaluate the validity of the experimental protocol, we first analyzed the distribution of the vacuolar proton pumping v-ATPase that is generally located in the membrane of endosomal and lysosomal organelles, and also of synaptic vesicles (Finbow and Harrison, 1997) (Fig. 4(A)). As expected for a ubiquitous protein, the enzyme was found to be distributed within all cellular elements of the section. In the single confocal optical sections, astrocytes and their processes could clearly be discerned by their EGFP fluorescence. An overlay of the EGFP fluorescence (green) and the immunofluorescence (red) demonstrated that v-ATPase containing organelles were associated with astrocytes (Fig. 4(A)). Punctae were frequent in the cell periphery and also within astrocytic processes. These data showed that confocal imaging can be applied to allocate the immunofluorescence of vesicular organelles to astrocytes and their processes in situ.

We then investigated the distribution of secretory carrier membrane protein I that has been found in the membrane of secretory organelles including synaptic vesicles (Fernández-Chacón et al., 1999). The distribution of SCAMP I was similar to that of v-ATPase. It was equally expressed by neurons and astrocytes. Within astrocytes, 


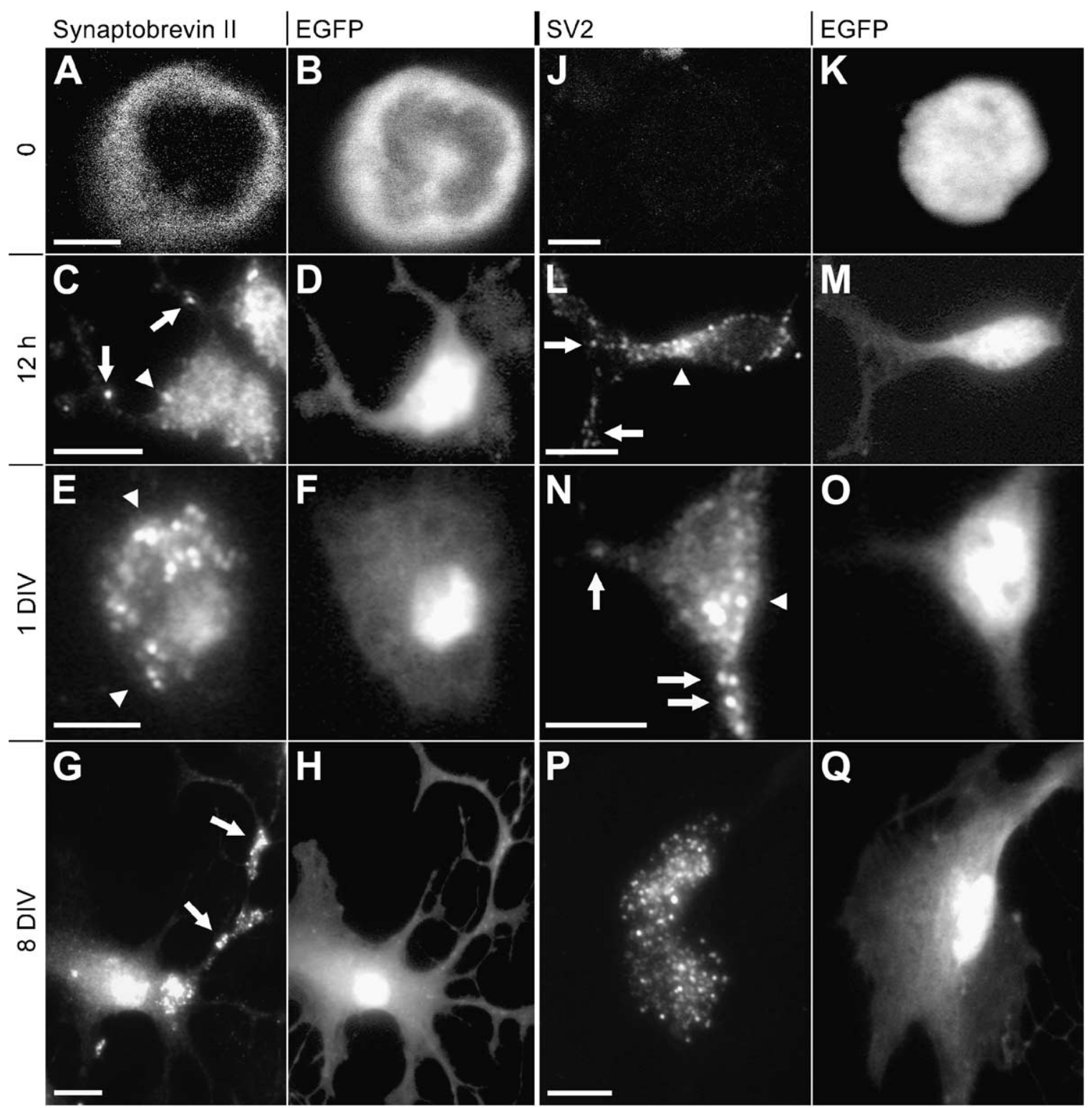

Fig. 3. Immunodetection of synaptobrevin II and SV2 in EGFP-expressing cells isolated from 11 day-old animals. Cells were fixed directly after isolation (A, B, J, K) or after culturing for $12 \mathrm{~h}(\mathrm{C}, \mathrm{D}, \mathrm{L}, \mathrm{M}), 1 \mathrm{DIV}(\mathrm{E}, \mathrm{F}, \mathrm{N}, \mathrm{O})$ and 8 DIV (G, H, P, Q). A, C, E, G, distribution of synaptobrevin II; J, L, N, P, SV2. Note the absence of indirect SV2 immunofluorescence in freshly isolated astrocytes. B, D, F, H, K, M, O, Q represent the corresponding distribution of EGFP fluorescence. Arrows, punctuate immunofluorescence in cellular extensions; arrow heads, punctuate staining in cell bodies. Images were adjusted to improve brightness and contrast. Scale bars: $10 \mu \mathrm{m}$.

SCAMP I revealed a punctuate immunofluorescence at the cell periphery and also within astrocytic processes and their ramifications (Fig. 4(B)). Whereas SNAP-23 was ubiquitously expressed by astrocytes (Fig. 4(D)), SNAP-25 (Fig. 4(C)) was observed only in a very small proportion $(<5 \%)$ of astrocytes. The intracellular distribution of SNAP-25 and of SNAP-23 was very similar to that of $\mathrm{v}$-ATPase and of SCAMP. It was high in the cell periphery and within astrocytic processes. The immunofluorescent dots were coarser for SNAP-25. A fine punctuate immunofluorescence could be detected for the ubiquitous vesicle protein cellubrevin (Fig. 4(E)) and the synaptic vesicle-associated protein synaptobrevin II (Fig. 4(F)). They were found to be expressed at high density throughout neurons and astrocytes including their processes. Punctuate synaptophysin immunofluorescence could be allocated only to a very small proportion $(<5 \%)$ of astrocytes (Fig. $4(\mathrm{G})$ ). In accordance with the results obtained with acutely isolated astrocytes, the ubiquitous synaptic vesicle protein SV2 could not be identified within astrocytes in situ (Fig. 4(H)). The results obtained with SV2 can be regarded as an important internal control. They exclude the possibility that astrocytic processes and presynaptic terminals appear in the same confocal plain. 

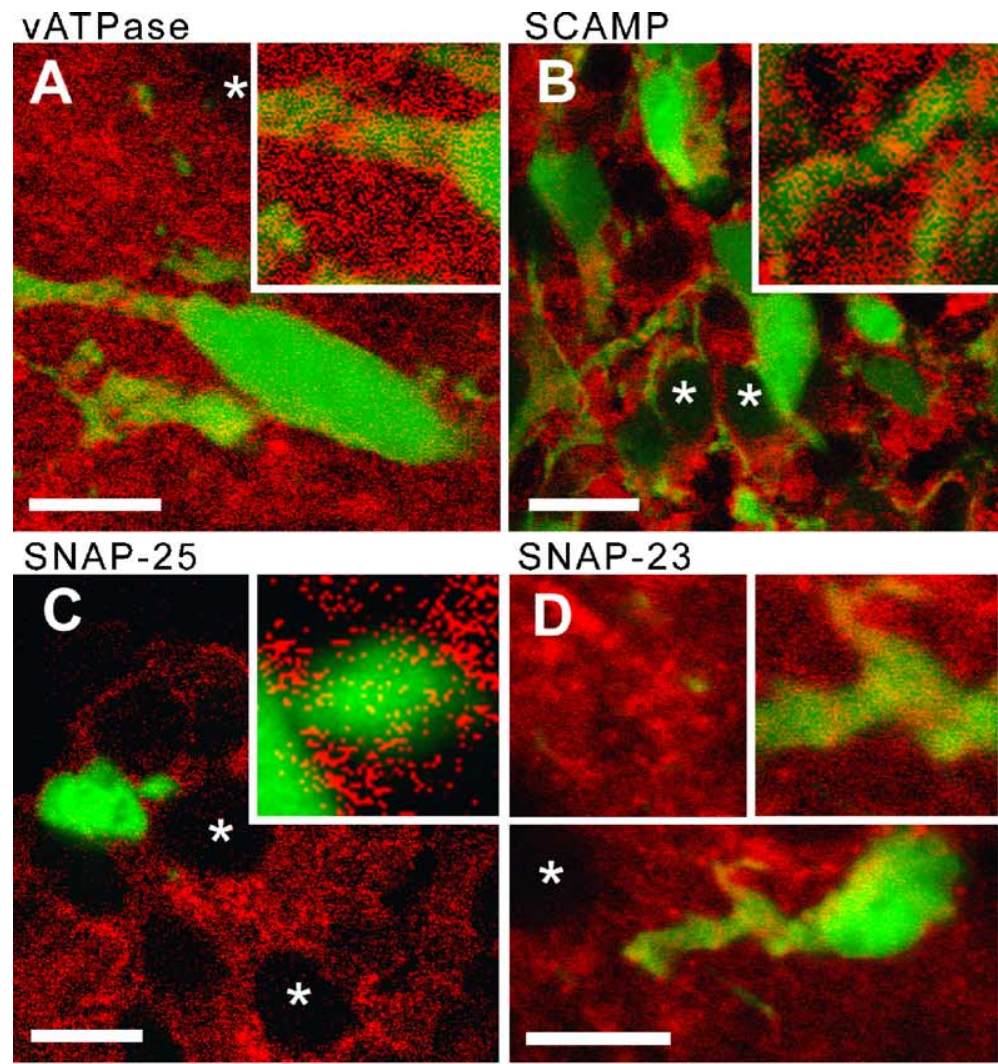

SNAP-23
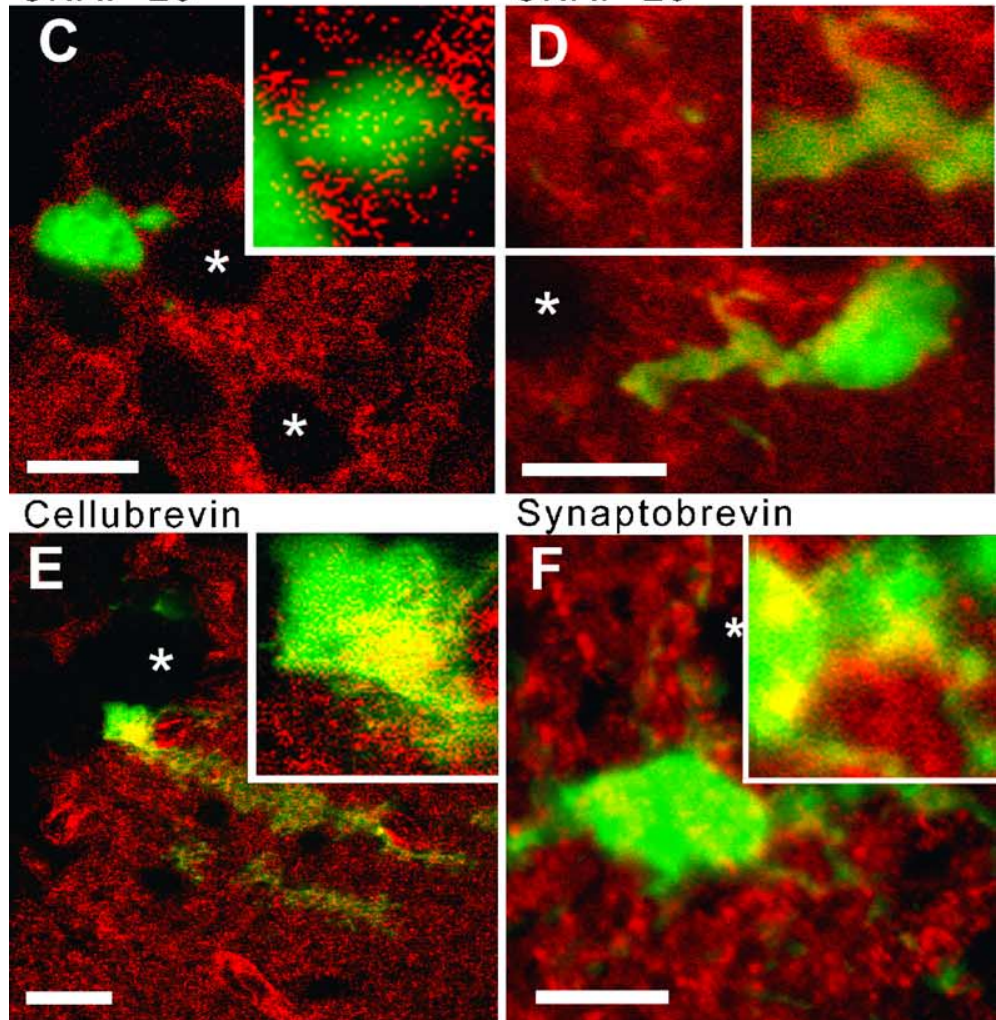

Synaptobrevin
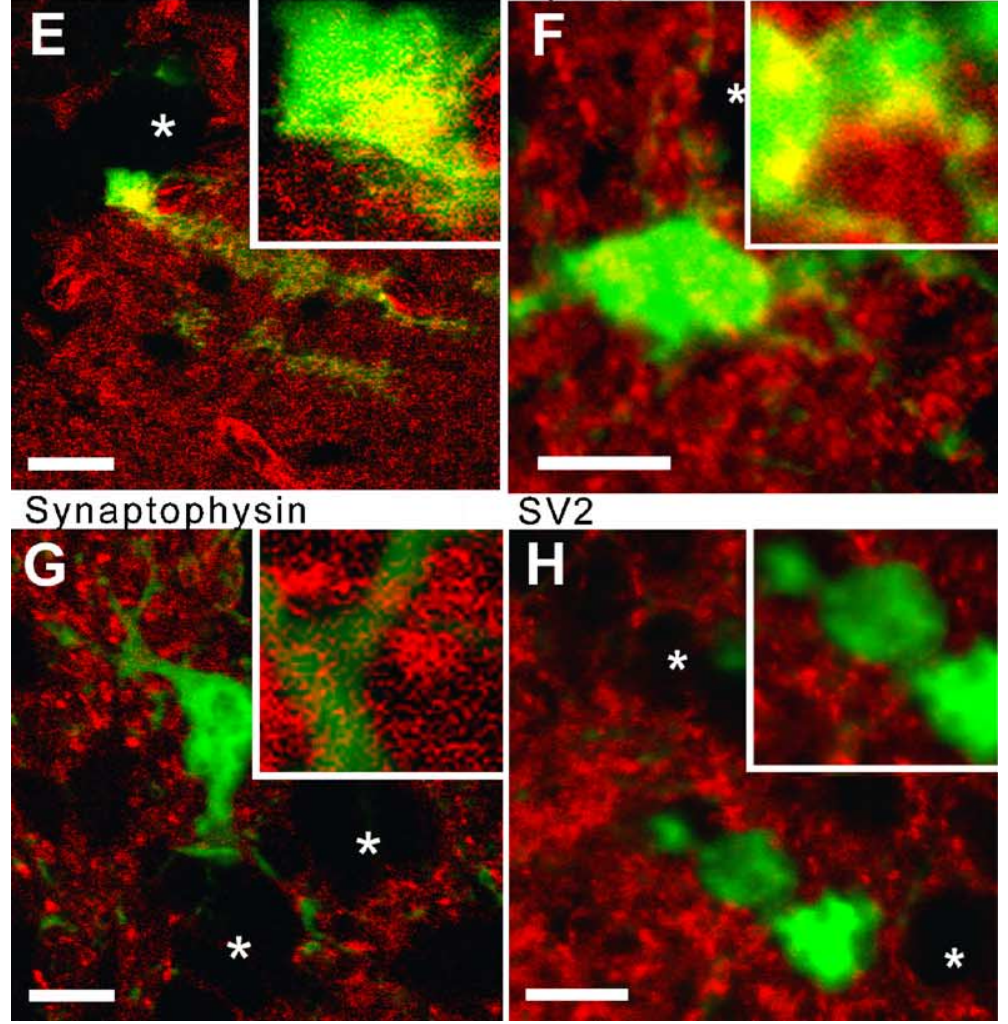

Fig. 4. Immunodetection of synaptic proteins in EGFP-expressing cells in situ. Coronal forebrain sections were derived from 1 day (A-E, G, H) or 16 days (F) old animals. Immunofluorescence was analyzed by confocal microscopy (single confocal optical sections). (A) v-ATPase; (B) SCAMP; (C) SNAP-25; (D) SNAP-23; (E) cellubrevin; (F) synaptobrevin II; (G) synaptophysin; (H) SV2. Insets represent digital zooms highlighting co-localization of EGFP and the respective proteins. $*$ in A-H depict examples of immunonegative nuclei of nerve cells. Images were adjusted to improve brightness and contrast. Scale bars: $10 \mu \mathrm{m}$. 


\section{Discussion}

This study suggests that cultured astrocytes derived from mice of varying age express a number of synaptic proteins not present in astrocytes in situ. Vesicular organelles in the vast majority of astrocytes in situ differ in protein composition from synaptic vesicles and neurosecretory granules. They contain the t-SNARE SNAP-23 rather than SNAP-25 and they lack typical synaptic vesicle proteins such as synaptophysin or SV2. They share with nerve terminals, however their contents in the v-SNAREs synaptobrevin II and cellubrevin.

We have previously shown (Maienschein et al., 1999) that astrocytes cultured from new born (1 day) rats and identified by GFAP-immunofluorescence are capable of expressing a plethora of synaptic proteins. At that developmental stage, rodent brain contains immature astroglial cells as the major proliferative cell population. Astrocytes from cortices of new born rats consist of a mixture of type- 1 astrocytes, O2A progenitor cells, and type 2 astrocytes (Juurlink and Hertz, 1992). The potential to express synaptic proteins may therefore represent a feature of immature or undifferentiated astrocytes. When cultured for 2 days, the EGFP-positive astrocytes isolated from 2 to 16 day-old mice revealed a punctuate organellar staining for the two synaptic vesicle proteins SV2 and synaptophysin and for the two t-SNAREs SNAP-25 and SNAP-23, as did GFAP-immunopositive astrocytes previously cultured from new born rats (Maienschein et al., 1999; Volknandt, 2002). This suggests that also mature astrocytes express synaptic proteins when transferred into tissue culture.

Since the expression of synaptic proteins could represent a general astrocytic response to isolation and culturing, we compared astrocytes isolated from young animals (11 days) immediately after isolation and after culturing for up to 8 DIV. Immediately after isolation, EGFP-fluorescent cells revealed an intense punctuate immunofluorescence for the t-SNARE SNAP-23 as well as for the synaptic vesicle protein and v-SNARE synaptobrevin II. In contrast, the ubiquitous synaptic vesicle protein SV2, a putative transporter protein (Bajjalieh et al., 1992), was absent from acutely isolated astrocytes, and SNAP-25 and synaptophysin immunoreactivity were detectable only in a minority of cells. All proteins became, however, abundantly expressed when astrocytes were cultured. This demonstrates that culturing can induce astrocytes to express proteins that in situ are typically neuron-associated (Südhof, 1995). This expression can be transient. We have previously shown that SNAP-25 becomes replaced on continued culturing by SNAP-23 and synaptophysin becomes down regulated (in contrast to synaptobrevin II) (Maienschein et al., 1999; Volknandt, 2002). An obvious feature of the immunopositive organelles in the cultured cells is their large apparent size, reminiscent of endosomes. Possibly culturing causes a rapid redistribution of organelle-associated proteins and their sorting into membrane compartments that differ in size and cellular distribution from those in situ.

Astrocytes in situ contained many organellar structures immunofluorescent for the vesicle-associated v-ATPase and SCAMP I. SCAMP I-SCAMP III are universally expressed and particularly enriched in organelles that undergo regulated exocytosis, such as mast cell granules and synaptic vesicles. But SCAMPs are also found in cell types (hepatocytes, fibroblasts) that have no apparent regulated transport pathway and apparently represent general markers of cell surface recycling pathways (Brand and Castle, 1993). SCAMP I appears to be present at high levels on synaptic vesicles that lack SCAMPs II and III (Fernández-Chacón et al., 2000). The astrocytic organellar localization of SCAMP I would thus be compatible with a regulated release pathway.

The pattern of immunostaining in astrocytes in situ closely corresponded to that of acutely isolated astrocytes. SNAP-23 was the predominant astrocytic t-SNARE. Astrocytes were also rich in organelles containing the v-SNAREs synaptobrevin II and cellubrevin but very few cells were found to express synaptophysin. The two related v-SNAREs synaptobrevin II and cellubrevin have been identified in a variety of cellular systems. In neurons, synaptobrevin II is thought to be associated with secretory vesicles whereas cellubrevin largely resides in recycling endosomes (McMahon et al., 1993).

The expression of SNAP-25 and synaptophysin in only a very small proportion of EGFP-expressing cells raises the possibility that in situ astrocytes reveal some heterogeneity regarding their organellar protein expression pattern. Although we have not addressed this question in detail this would be in a accordance with previously observed heterogeneities in astrocytic expression of peptides (Calegari et al., 1999) and receptors for neurotransmitters (Hösli and Hösli, 1993, Matthias et al., 2003), or in their physiological membrane properties (Nolte et al., 2001).

Taken together, our data suggest that astrocytes in situ carry a vesicular membrane compartment with the potential for regulated exocytosis. However, the molecular players involved in organelle function and regulated exocytosis probably differ from those in nerve terminals.

\section{Acknowledgements}

This study was supported by Deutsche Forschungsgemeinschaft (Vo 423/7-1) and the Fonds der Chemischen Industrie). We thank Norbert Braun for valuable advice and Klaus Hammer for excellent technical support.

\section{References}

Araque, A., Carmignoto, G., Haydon, P.G., 2001. Dynamic signaling between astrocytes and neurons. Annu. Rev. Physiol. 63, 795-813. 
Araque, A., Li, N.Z., Doyle, R.T., Haydon, P.G., 2000. SNARE protein-dependent glutamate release from astrocytes. J. Neurosci. 20, 666-673.

Bajjalieh, S.M., Peterson, K., Shinghal, R., Scheller, R.H., 1992. SV2, a brain synaptic vesicle protein homologous to bacterial transporters. Science 257, 1271-1273.

Bal-Price, A., Moneer, Z., Brown, G.C., 2002. Nitric oxide induces rapid, calcium-dependent release of vesicular glutamate and ATP from cultured at astrocytes. Glia 40, 312-323.

Bezzi, P., Carmignoto, G., Pasti, L., Vesce, S., Rossi, D., Rizzini, B.L., Pozzan, T., Volterra, A., 1998. Prostaglandins stimulate calciumdependent glutamate release in astrocytes. Nature 391, 281-285.

Brand, S.H., Castle, J.D., 1993. SCAMP 37, a new marker within the general cell surface recycling system. EMBO J. 12, 3753-3761.

Calegari, F., Coco, S., Taverna, E., Bassetti, M., Verderio, C., Corradi, N., Matteoli, M., Rosa, P., 1999. A regulated secretory pathway in cultured hippocampal astrocytes. J. Biol. Chem. 274, 22539-22547.

Coco, S., Calegari, F., Pravettoni, E., Pozzi, D., Taverna, E., Rosa, P., Matteoli, M., Verderio, C., 2003. Storage and release of ATP from astrocytes in culture. J. Biol. Chem. 278, 1354-1362.

Fernández-Chacón, R., De Toledo, G.A., Hammer, R.E., Südhof, T.C., 1999. Analysis of SCAMP1 function in secretory vesicle exocytosis by means of gene targeting in mice. J. Biol. Chem. 274, 32551-32554.

Fernández-Chacón, R., Achiriloaie, M., Janz, R., Albanesi, J.P., Südhof, T.C., 2000. SCAMP1 function in endocytosis. J. Biol. Chem. 275, $12752-12756$.

Finbow, M.E., Harrison, M.A., 1997. The vacuolar $\mathrm{H}^{+}$-ATPase: a universal proton pump of eukaryotes. Biochem. J. 324, 697-712.

Haydon, P.G., 2001. Glia: listening and talking to the synapse. Nat. Rev. Neurosci. 2, 185-193.

Heimer, G.V., Taylor, C.E., 1974. Improved mountant for immunofluorescence preparations. J. Clin. Pathol. 27, 254-256.

Hepp, R., Perraut, M., Chasserot-Golaz, S., Galli, T., Aunis, D., Langley, K., Grant, N.J., 1999. Cultured glial cells express the SNAP-25 analogue SNAP23. Glia 27, 181-187.

Hösli, E., Hösli, L., 1993. Receptors for neurotransmitters on astrocytes in the mammalian central nervous system. Prog. Neurobiol. 40, 477-506.

Jeftinija, S.D., Jeftinija, K.V., Stefanovic, G., 1997. Cultured astrocytes express proteins involved in vesicular glutamate release. Brain Res. $750,41-47$.

Juurlink, B.H.J., Hertz, L., 1992. Astrocytes. In: Boulton, A., Bakar, G., Walz, W. (Eds.), Practical Cell Culture Techniques. Humana Press, Tatowa, NJ. pp. 269-321.

Krzan, M., Stenovec, M., Kreft, M., Pangrsic, T., Grilc, S., Haydon, P.G., Zorec, R., 2003. Calcium-dependent exocytosis of atrial natriuretic peptide from astrocytes. J. Neurosci. 23, 1580-1583.
Madison, D.L., Krüger, W.H., Kim, T., Pfeiffer, S.E., 1996. Differential expression of rab3 isoforms in oligodendrocytes and astrocytes. J. Neurosci. Res. 45, 258-268.

Maienschein, V., Marxen, M., Volknandt, W., Zimmermann, H., 1999. A plethora of presynaptic proteins associated with ATP-storing organelles in cultured astrocytes. Glia 26, 233-244.

Matthias, K., Kirchhoff, F., Seifert, G., Hüttmann, K., Matyash, M., Kettenmann, H., Steinhäuser, C., 2003. Segregated expression of AMPA-type glutamate receptors and glutamate transporters defines distinct astrocyte populations in the mouse hippocampus. J. Neurosci. $23,1750-1758$.

McMahon, H.T., Ushkaryov, Y.A., Edelmann, L., Link, E., Binz, T., Niemann, H., Jahn, R., Südhof, T.C., 1993. Cellubrevin is a ubiquitous tetanus-toxin substrate homologous to a putative synaptic vesicle fusion protein. Nature 364, 346-349.

Megías, L., Guerri, C., Fornas, E., Azorin, I., Bendala, E., Sancho-Tello, M., Durán, J.M., Tomás, M., Gomez-Lechon, M.J., Renau-Piqueras, J., 2000. Endocytosis and transcytosis in growing astrocytes in primary culture. Possible implications in neural development. Int. J. Dev. Biol. 44, 209-221.

Nolte, C., Matyash, M., Pivneva, T., Schipke, C.G., Ohlemeyer, C., Hanisch, U., Kirchhoff, F., Kettenmann, H., 2001. GFAP promoter-controlled EGFP-expressing transgenic mice: a tool to visualize astrocytes and astrogliosis in living brain tissue. Glia 33, 72-86.

Parpura, V., Basarsky, T.A., Liu, F., Jeftinija, K., Jeftinija, S., Haydon, P.G., 1994. Glutamate-mediated astrocyte-neuron signalling. Nature 369, 744-747.

Parpura, V., Fang, Y., Basarsky, T., Jahn, R., Haydon, P.G., 1995. Expression of synaptobrevin II, cellubrevin and syntaxin but not SNAP-25 in cultured astrocytes. FEBS Lett. 377, 489-492.

Parri, H.R., Gould, T.M., Crunelli, V., 2001. Spontaneous astrocytic $\mathrm{Ca}^{2+}$ oscillations in situ drive NMDR-mediated neuronal excitation. Nat. Neurosci. 4, 803-812.

Pasti, L., Volterra, A., Pozzan, T., Carmignoto, G., 1997. Intracellular calcium oscillations in astrocytes: a highly plastic, bidirectional form of communication between neurons and astrocytes in situ. J. Neurosci. 17, 7817-7830.

Pasti, L., Zonta, M., Pozzan, T., Vicini, S., Carmignoto, G., 2001. Cytosolic calcium oscillations in astrocytes may regulate exocytotic release of glutamate. J. Neurosci. 21, 477-484.

Südhof, T.C., 1995. The synaptic vesicle cycle: a cascade of proteinprotein interactions. Nature 375, 645-653.

Vesce, S., Bezzi, P., Volterra, A., 1999. The active role of astrocytes in synaptic transmission. Cell Mol. Life Sci. 56, 991-1000.

Volknandt, W., 2002. Vesicular release mechanisms in astrocytic signalling. Neurochem. Int. 41, 301-306. 